\title{
0 Departamento de Ecologia
}

\author{
Maria de Nazaré Góes Ribeiro $\left(^{*}\right)$
}

\section{Resumo}

O Departamento de Ecologia do Instituto Nacional de Pesquisas da Amazônia, teve início no ano de 1970 com o nome de Secção de Fatores Ambientais, que compreendia os laboratórios de Climatologia, $\mathrm{Hi}$ drologia, Limnologia e Pedobiologia. Em 1971, o Sr Diretor do INPA, Dr. Paulo de Almeida Machado, dando nova estrutura à Instituição, transformou a Secção de Fatores Ambientais em Divisão de Ciências do Ambiente. Em 1975, foi estruturado o Departamento de Ecologia que tuncionou com 3 Divisões: Ciências do Ambiente, Limnologia e Pedobiologia. A partir de 1979, - Departamento de Ecologia vem funcionando com 4 Divisōes de Pesquisas: Ciências do Ambiente, Bioecologia, Limnologia e Entomologia. unas atividades de pesquisas estão voltadas para o estudo do ambiente físico e químico dos organismos; enfatizando os grandes ciclos da água, do carbono, dos nutrientes minerais, bem como o balanço de energia, nos grandes ecossistemas da Amazônia; para o estudo da ecologia de populações e comunidades biológicas incluindo 0 Homem; dedicando-se ao estudo dos processos ecológicos nos rios e lagos da Amazônia; e o estudo da sistemática e ecologia dos insetos. O Departamento conta com a colaboração de 31 pesquisadores sendo 14 Ph.D (3 visitantes), 9 M.Sc (1 visitante) e 8 graduados.

\section{INTRODUÇÃO}

No exercício 1970-1972, o Instituto Nacional de Pesquisas da Amazônia, teve como Diretor o Dr. Paulo de Almeida Machado.

Em 1970, dentro da estrutura do INPA, existiu o Centro de Pesquisas Florestais (CPF) lo. calizado no centro da maior área florestal do mundo e levou o INPA a encarar a pesquisa florestal como preocupação básica.

Do Centro de Pesquisas Florestais fazia parte, entre outras, a Seção de Fatores Ambientais que compreendia os laboratórios de Climatologia, Hidrologia, Limnologia e Pedobiologia.

Considerando o estudo do microclima flo. restal, do solo e das águas de fundamental importância no programa integrado de pesqui- sa florestal, a Seção organizou o Simpósio sobre Fatores Ambientais, que se realizou em Manaus-AM e contou com a participação do cientistas dos Estados Unidos, Alemanha e Brasil.

O Simpósio se desenvolveu em três sessões: duas foram realizadas nos meses de abril e setembro/70; cada uma teve a duração de 30 dias, compreendendo pesquisas de campo; e a terceira realizou-se em junho/71.

Com o êxito alcançado no Simpósio, a Seção de Fatores Ambientais teve oportunidade ae expandir-se, contando com a colaboração do National Center for Atmospheric Research (NCAR).

Os membros participantes da $3 .^{\circ}$ sessão do Simpósio sobre Fatores Ambientais foram: J.P. Lodge; J.B. Pate; D. Scheesley, do National Center for Atmospheric Research; J. Weinman, da Universidade de Wiscousin; N. Stark, do Desert Research Institute de Nevada; E.L. Tyson, do Center for Tropical Studies, Universidade de Miami; R. Hutton, do Annex State College; G.T. Prance, do Jardim Botâ. nico de New York; O.R. Gottlieb, da UFRRJ; L. Pitombo, da Universidade de São Paulo representando o CNPq; P.A. Machado; W.L.F. Brinkmann; V.C. Araujo; Antonio dos Santos; M.N. Góes Ribeiro; Eleazer Volpato, do INPA e C.W. van Scarpenzel, Chefe do Serviço Meteorológico de Suriname (INPA, 1970).

A Seção de Fatores Ambientais teve como responsável o Dr. W.L.F. Brinkmann, Ph.D.

No exercício de 1971, o Sr. Diretor do INPA, Dr. Paulo de Almeida Machado, dando uma nova estrutura à Instituição, transformou a Seção de Fatores Ambientais em Divisão de Ciências do Ambiente e os laboratórios pas. saram a ser considerados setores.

A Divisão de Ciências do Ambiente, con. siderada pelo $\mathrm{Sr}$. Diretor como ponto alto do INPA, continuou destacando-se no estudo dos

(*) - Instituto Nacional de Pesquisas da Amazônia, Manaus. 
fatores ambientais relacionados com a vida na Amazônia. No setor de Limnologia, salientouse o grupo com os trabalhos de Santos (1979) elucidando o problema da mortandade de peixes durante a "friagem". No Setor de Hidrolcgia evidenciaram-se os trabalhos de Brinkmann \& Santos (1971 e 1973) sobre o ciclo de elementos. No Setor de Climatologia, contouse com os trabalhos pioneiros de Brinkmann \& Ribeiro (1971a, b) sobre a temperatura do solo na região terciária da Amazônia Central, temperaturas medidas durante um ano a três profundidades diferentes, em solos agriculturado, além de trabalhos originais de Brinkmann (1971) sobre a intensidade e composição espectral da luz em diversos níveis na floresta Amazônica .

O Setor de Pedobiologia com laboratório instalado recentemente, organizado pelo $\mathrm{Dr}$. Herbert Otto Roger Schubart, iniciou o estudo das populações, procedendo a um levantamento qualitativo e quantitativo, estabelecendo bases para o estudo do papel da micro-fauna do solo na decomposição de litter e ciclo dos elementos (INPA, 1971).

Brinkmann \& Ribeiro (1972) realizaram medidas climatológicas em uma clareira e uma capoeira na Reserva Florestal Ducke do INPA, durante a friagem ocorrida no dia 10 de julho de 1969. As temperaturas foram medidas em duas torres improvisadas em 8 diferentes niveis, na amplitude de 10 a $900 \mathrm{~cm}$ de altura. A temperatura mínima absoluta do dia foi de $11.0^{\circ} \mathrm{C}$ sendo excepcionalmente baixa para a Amazônia Central e aproximadamente $16.0^{\circ} \mathrm{C}$ abaixo da temperatura média anual da cidade de Manaus. Os perfís de temperatura na clareira e na capoeira na Reserva Ducke, durante a friagem não se enquadram com a situação estabelecida para o ambiente tropical.

Estudos hidrológicos realizados por Matsui et al., (1972), encontraram concentrações isotópicas diferentes nas águas do rio Negro e do rio Solimões. Os dados obtidos permitiram com razoável precisão o cálculo da vazão re. lotiva de ambos os rios para alguns meses. Verificou-se que a $120 \mathrm{~km}$ da confluência do Negro e Solimões, ainda não havia mistura perfeita a que, abaixo daquele ponto, a con. fluência do Madeira introduz perturbações na mistura.

Brinkmann (1972), estudando o lago do Castanho a cada 10 minutos mediu a luz total incidindo sobre a superfície do lago e a luz difusa abaixo da superfície do lago. Verificou-se nas camadas superficiais da água do lago, intensidade luminosa suficiente para assegurar c desenvolvimento de organismos foto-autotróficos, com variações mínimas durante o dia. Embaixo das massas de capim flutuante, a intensidade da luz difusa era extremamente baixa, máximo 20 Lux.

Schubart realizou estudos sobre os microartrópodos do solo envolvidos na decomposição do litter e os estudos de B. Cavalcante e de O.M. Fonseca sobre os fungos envolvidos na decomposição do litter e no ciclo de nutrientes. Da soma de informações fornecidas pela pesquisa básica irão surgir dados úteis fara a compreensão da ecologia florestal (INPA, 1972).

Em fins de 1972, a Divisão de Ciências do Ambiente mudou-se da Sede provisória do INPA localizada na Rua Guilherme Moreira para o seu pavilhão construído na Sede do INPA localizada na Estrada do Aleixo (Fig. 1).

No exercício de 1973, na administração do Dr. Mário Honda, o Setor de Ciências do Ambiente publicou os primeiros dados sobre a ciclagem de nutrientes no solo florestal (INPA 1973).

Foram estudadas as modificações na composição química do solo na camada superior do solo (até $20 \mathrm{~cm}$ ) em latossolos amarelos ( $85 \%$ da área total) antes e depois da queima da mata derrubada (Brinkmann \& Nascimento, 1973).

Na região terciária Amazônica próxima a Manaus, as principais fontes de cálcio encontradas na água são: a água escorrendo sobre os troncos e a água total da floresta. O teor em cálcio solúvel deve ser proveniente da lavagem, pela chuva, da copa, dos caules, folhas e. até um certo ponto, da dissolução de produ. tos metabólicos de macro e micro-organismos (INPA, 1973). 


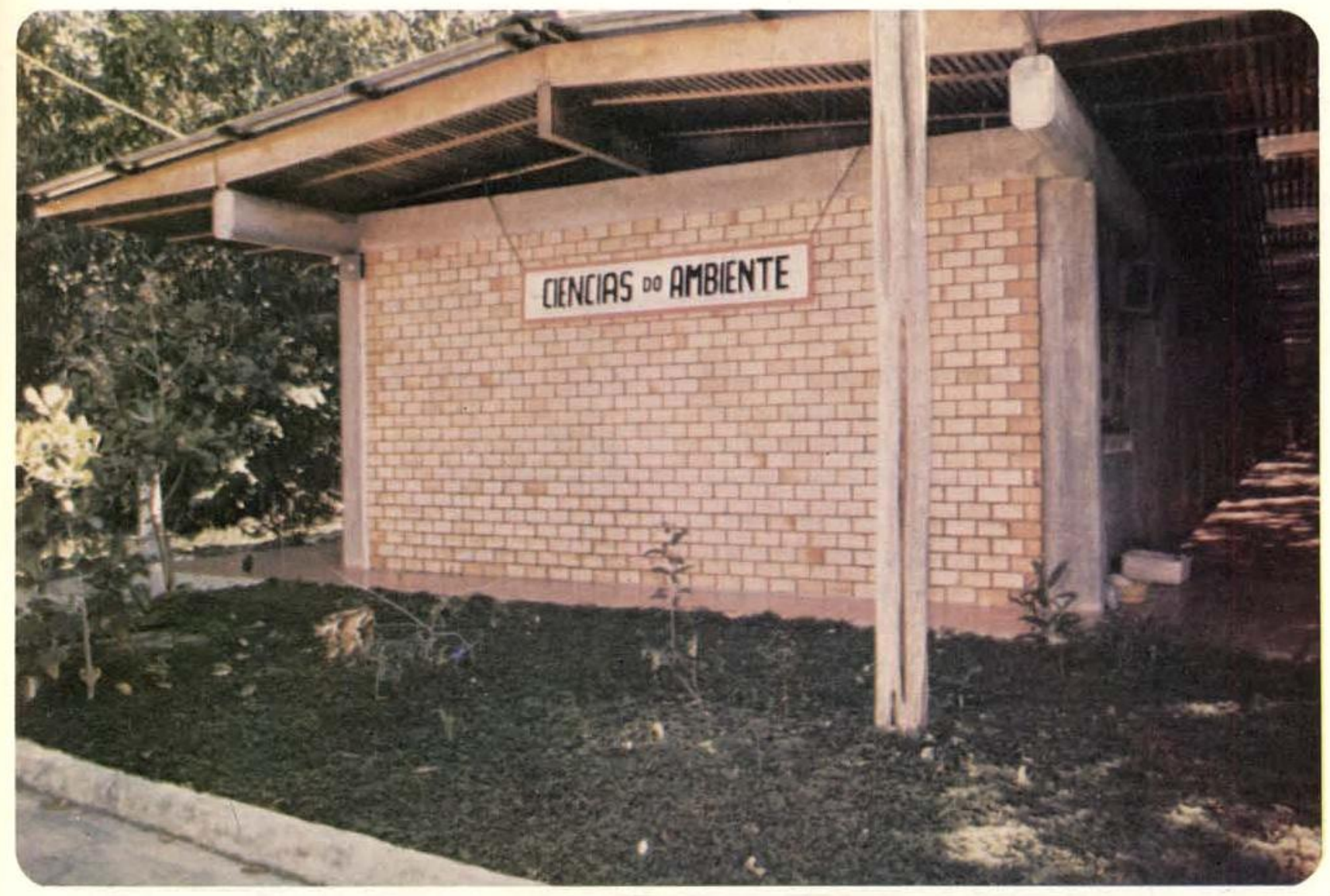

Fig. 1 - Pavilhão da Divisão de Ciências do Ambiente na sede do INPA, Estrada do Aleixo.

No exercício 1974-1978, na administração do Dr. Warwick Estevam Kerr, o Instituto Nacional de Pesquisas da Amazônia funcionou com seis Divisões de Pesquisas tendo entre elas a Divisão de Biologia, dentro da qual se situavam os Departamentos de Botânica, Ecologia, Entomologia e Genética.

O Departamento de Ecologia foi estruturado no início de 1975 , sob a coordenação do ecólogo e biologista de solos $\mathrm{Dr}$. Herbert Otto Roger Schubart, contando com 20 pesquisadores ( 4 doutores e 3 mestres), além de alunos de Pós-Graduação em Ecologia e de pesquisadores visitantes.

O Departamento funcionou com 3 Divisões : Ciências do Ambiente, Limnologia e Pedobiologia.

A Divisão de Ciências do Ambiente, tendo como responsável a Pesquisadora Assistente Dra. Maria de Nazaré Góes Ribeiro, desenvolveu atividades de pesquisas nas áreas de Meteorologia e Hidrologia (Fig. 2).
Estudos microclimatológicos no ecossistema Campina Amazônica para caracterização do solo arenoso com sua vegetação natural em equilíbrio biológico, que forneceram subsídios às pesquisas ecológicas em desenvolvimento na Região (Ribeiro \& Santos, 1975).

Foram verificados que as principais fontes de nitrogênio na água do solo do ecossistema Campina Amazônica são : o material em decomposição, chuva, água de lavagem da floresta e produtos do metabolismo de microorganismos; e, que o solo de areia branca em condições naturais, não é fator limitante para o desenvolvimento da vegetação natural (Santos \& Ribeiro, 1975).

Foi classificado, de modo claro e objetivo, o clima de Manaus pelos métodos de Köppen e Thornthwaite, com dados meteorológicos da Estação Meteorolósica da Reserva Florestal Ducke do INPA (Ribeiro, 1976).

$\mathrm{Em}$ estudo realizado para estimativa da evapotranspiração na Bacia Amazônica, os da- 
dos indicam que $90 \%$ da evapotranspiração se devem ao balanço de energia. A evapotranspiração real deve, nesta região, ser aproximadamente igual à potencial, e a média encontrada foi da ordem de $4 \mathrm{~mm} / \mathrm{dia}$, ou seja $1460 \mathrm{~mm} /$ ano. Desde que a transpiração pelas plantas representa $61,8 \%$ do balanço hídrico, tudo indica que um desmatamento intensivo deverá trazer alterações no ciclo hidrológico (Villa Nova et al., 1976).

O coeficiente de transmissão da radiação global para o dia $11 / 06$ foi de 0,81 valor este que deverá ser representativo para dias lim. pos no mês de junho; enquanto não houver poluição atmosférica acentuada, este coeficiente poderá ser tomado como representativo para dias limpos em Manaus (Villa Nova et al., 1976).

Os dados estimados de geotemperaturas da Reserva Ducke-Manaus referentes ao período 1965-1975 indicam que nos meses de setembro, outubro e novembro a temperatura da superfície do solo atinge seus valores mais al- tos da ordem de $46^{\circ} \mathrm{C}$ e, nos demais meses do ano, em torno de $43,5^{\circ} \mathrm{C}$. Os solos da região estudada e com cobertura de grama rasteira

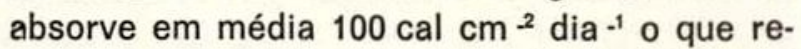
presenta em média $24 \%$ da radiação solar global (Decico et al., 1977).

O fluxo de vapor e a água precipitável foram computados sobre a floresta natural Amazônica na faixa entre Belém e Manaus para o ano de 1972, de onde se concluiu que o vapor d'água oriundo do Oceano Atlântico contribui com $52 \%$ para a precipitação na região e é significativo o papel desempenhado pela eva. potranspiração local para a precipitação na área; existem indícios do fenômeno da reciclagem do vapor d'água durante o ano. A evapo. transpiração contribui com $48 \%$ para a precipitação na área estudada (Marques et al., 1977).

Foram estudados os ventos em altitudes sobre Belém e Manaus a partir de informaçôes de 364 e 294 sondagens aerológicas, respectivamente, perfazendo um total de 658 son-

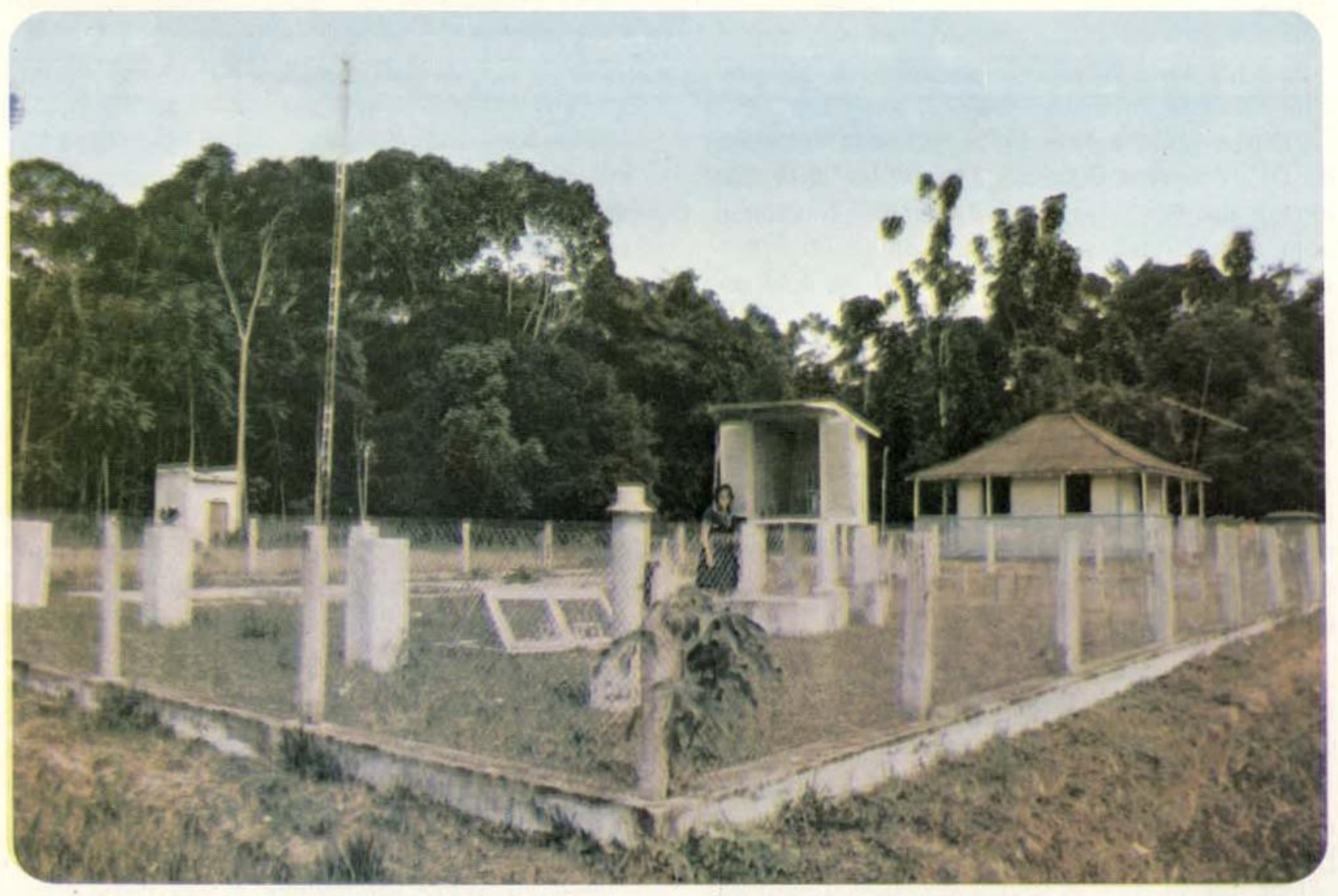

Fig. 2 - Estação Metereológica do INPA, Reserva Florestal Ducke. 
dagens. Verificou-se que a componente sazonal, tanto em Manaus quanto em Belém, foi no sentido Leste para Oeste durante todo o ano e em todos os níveis estudados e que os valores máximos encontram-se próximos aos 1500 metros em ambas as localidades (Marques et al., 1978).

Com medidas de radiação solar global realizadas no INPA em Manaus-AM, no período 1976-1977, concluiu-se que :

a) a radiação solar global média do ano é

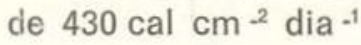

b) o valor máximo obtido no período foi de $670 \mathrm{cal} \mathrm{cm}^{-2} \mathrm{dia}^{-1}$ em 18/11/76

c) os valores médios mensais maiores ocorrem no período de agosto-setembro e os médios mensais menores, no período de janeiro a março (Villa Nova et al., 1978) .

Editado o Anuário Meteorológico do INPA, este constitui-se um relevante serviço desta Instituição, referente aos anos: 1965/77, com dados coletados na Estação Meteorológica do INPA localizada na Reserva Ducke, Km 26 da Manaus-Itacoatiara (Ribeiro, 1977).

Instalou-se um Posto Meteorológico na itha do Careiro, com o objetivo de estudar os fatores climáticos que influenciam as condições ecológicas, em lagos de várzeas da Ama. zônia Central.

A emissão de $\mathrm{H}_{2} \mathrm{~S}$ dos lagos de várzea da Amazônia Central dá-se principalmente durante o período de rebaixamento do nível de água do rio Solimões (Amazonas), que atinge o seu mínimo entre setembro e outubro, em amostras de água de até $0,40 \mathrm{mg} / \mathrm{l}$ de $\mathrm{S}$, em condições especiais.

Uma parte do $\mathrm{H}_{2} \mathrm{~S}$ emitido é recirculado numa escala regional ou local através da biosfera e posteriormente, arrastado por precipitações fechando o ciclo do enxofre da Amazônia. Entretanto, uma certa porção do $\mathrm{H}_{2} \mathrm{~S}$ emitido contribuiu para o balanço do enxofre atmosférico. Sob condições de frente fria, en. tretanto, o $\mathrm{H}_{2} \mathrm{~S}$ emitido é rapidamente recirculado nas vegetações das florestas tropicais (Santos, 1979).

As condições limnológicas no lago Grande Jutaí, na Amazônia Central, são determinadas principalmente pelo rio Solimões. O lago é conectado com o rio durante quase todo o ano e suas flutuações, conseqüentemente, afetam diretamente o lago. As mudanças no nível de água somam uma amplitude de 9 a 10 metros, anualmente. De janeiro a junho, encontra-se cheio com água de rio e chuva e de julho a dezembro encontra-se rebaixado. Essas flutuações em seu nível são as principais responsáveis pelas grandes variações físicas e biológicas ocorridas em seu meio. Os meses de maio, junho, julho e agosto e, às vezes, setemŁro, são considerados críticos para os peixes, face às pequenas concentrações de oxigênio ciissolvidas. Estas baixas concentrações de oxigênio são devidas a fenômenos de estagnação (favorecendo a formação de $\mathrm{H}_{2} \mathrm{~S}$ e redução de oxigênio) ou de turbulência (ocasionando a elevação do gás até à região do epilimínio e, conseqüentemente, a redução do oxigênio. O rio Solimões fertiliza os lagos durante a enchente e, ao mesmo tempo refertiliza-se no período do rebaixamento com o retorno das águas, dado fenômenos de remineralização (Santos, 1980).

A Divisão de Limnologia, nesta Adminis. tração contou com um número bem reduzido de pesquisadores exercendo atividades de pesquisas na Instituição, em virtude de um grande número dos mesmos terem-se deslocado para outras Instituições do País, para os cursos de Mestrado e Doutorado.

Deste modo, ficou respondendo pela Divisão o Pesquisador Assistente Ozório José de Menezes Fonseca.

Em 1976 e 1977, foram estudados cinco diferentes lagos, analisando-se a sua estrutura microbiana e os fatores ambientais, com ênfase em fungos decompositores de celulose. Foram levantados dados de poluição e autopurificação do rio Negro nas cercanias de Manaus (INPA, 1974-1978) e estudadas a distribuição geográfica e características fisiológicas de Chromobacterium violaceum, um importante microorganismo de solo e água (Guarim, 1979).

Em Manaus, foi estudado o papel do solo como reservatório natural de fungos patogêni cos para o homem e a influência das cond:ções climáticas no desempenho do solo co- 
mo elementos de reserva e dispersão desses eumicetos. Durante nove meses, em 35 locais do perímetro urbano da cidade, foram estudadas 315 amostras de solo e isolados fungos patogênicos ou potencialmente patogênicos paar o homem, tais como: Trichophyton mentagrophytes e Microsporum gypseum, além de outras ceratinofílicos entre os quais desponta como o mais freqüente o Chrisosporium tropicum. Outubro, com temperatura elevada e baixa pluviosidade, foi o mês de maior percentual de amostras contaminadas $(48,57 \%)$ e abril, com alta precipitação e temperatura mé. dia mais baixa, apareceu com o de menor infecciosidade de solo, com apenas $4,53 \%$ das amostras contaminadas com esses fungos.

Em Manaus, foi estudada a precipitação de esporos fúngicos em dois locais do perímetro urbano, durante doze meses. A alta incidência de esporos fúngicos no ar da cidade de Manaus, especialmente nos meses mais quentes pode explicar parcialmente a elevada taxa de pacientes portadores de alergoses do trato respiratório superior na mesma época. Não foi possivel achar uma correlação precisa entre o número de fungos no ar e os dados climatológicos disponíveis, mas é nítida a maior freqüência nos meses mais secos (INPA, 19741978),

Em 1978, foi iniciado o estudo sobre o último corpo de água que corta a cidade de Manaus e que ainda tem uma parte de seu curso sem os efeitos poluidores da cidade. Procedeu-se ao estudo de um lago de bacia de água preta, com o auxílio de quatro pós-graduandos, para análise em ciclo anual do fitoplâncton, zooplâncton, produtividade primária, fauna de benthos, estrutura microbiana e aspectos físico-químicos desse ambiente (INPA, 1974-1978).

A Divisão de Pedobiologia, tendo como responsável o Pesquisador Dr. Herbert Otto Roger Schubart, desenvolveu os estudos científicos referentes aos seus objetivos, a seguir:

Estudo ecológico-cultural da colonização ao longo da Transamazônica, abrangendo produtividade agrícola, utilização da caça, saúde e esquema de assentamento, apontando diversos erros e sugerindo soluções para o problema.
Um estudo de redes alimentares entre invertebrados de águas pretas que mostrou que o fluxo de energia nestes corpos d'água se ınicia com a decomposição de matéria orgânica alóctone e não com a produção primária autóctone, indicando que um desmatamento das margens dos igarapés e rios alteraria completamente a estrutura das comunidades aquáticas, dos protozoários até os peixes grandes. Tomando-se como exemplo as relações bióticas de uma ameba (Amoeba cf. discoides) verificou-se que 19 espécies de invertebrados entram direta ou indiretamente no fluxo alimentar da ameba a qual é um predador voraz não só de ciliados mas também de pequenos anelídeos (Walker, 1978).

As tecamebas (amebas que constroem carapaças de areia ou com excreção próprial apresentam grandes diversidades nos igarapés. No igarapé da Reserva da Campina foram encontrados 32 tipos diferentes (morfo-espécies) o que estimulou a procura e comparação em outros locais, a saber, 2 igarapés de água preta e 2 de água clara, todos comparáveis quanto à largura, vazão, vegetação. Os igarapés de água preta apresentam-se 2-3 vezes rais ricos em número de amebas por área Foram encontradas 80 morfo-espécies (todas catalogadas e desenhadas com câmara clara) no total. Cada igarapé tem algumas formas não encontradas nos outros 3 igarapés. Parece que formas muito semelhantes variam de maneira característica entre os igarapés, o que é bastante interessante do ponto de vista da evolução. Estudo potencialmente importante do ponto de vista de indicadores biológicos (Walker \& Lages, 1980).

Um levantamento da fauna de minhocas da Amazônia Central permitiu a descoberta de 6 novos gêneros, 23 novas espécies e 5 novas sub-espécies. Foram confirmadas novas ocorrências para o Amazonas e ampliada a distribuição geográfica de Pontoscolex corethurus. A drilofauna da região conta agora com 8 família, 21 gêneros e 38 espécies (INPA, 19741978).

O esiudo da ecologia de Andiorrhinus amazonicus mostrou que esta é uma espécie típica do húmus ácido, com reprodução na épo. 
ca das chuvas e sobrevivência na estiagem por estivaçäo. O efeito das estaçöes sobre a densidade populacional é diferente em função do habitat considerado. A ocorrência relativa dos diferentes estágios (Jovens, adultos não reprodutivos e adultos reprodutivos) depende das diferentes estações, predominando adultos na estiagem. A reprodução ocorre na época chuvosa. A densidade numérica total depende da estação do ano e do habitat, sendo a população sob a árvore "casca doce" significativamente menor, provavelmente pelo efeito de substâncias tóxicas desta planta, ou pela menor retenção de água neste tipo de húmus (INPA 1974-1978)

Estudo sobre biologia alimentar, de inse. tos colêmbolas, mostrou que a adição de sa carose e cultura de Onychiurus cunhai Arlé di. minuiu sua mortandade e estimulou sua reprodução muito provavelmente por via indireta, através do florescimento de bactérias e leveduras, que constituiram a verdadeira base alimentar (proteínas) do inseto (Rufino \& Schu bart, 1974).

Estudo da diversidade da fauna de térmi. tas na terra firme da Amazônia Central resultou na obtenção de 20 gêneros (14 na floresta primária, 14 na capoeira e 15 na pastagem). sendo mais comum o gênero Nasutitermes com trinta espécies. A pastagem revelou uma diversidade comparável à dos outros habitats Fato notável foi a constataçäo da fixação de $\mathrm{N}_{2}$ atmosférico por térmitas da pastagem (INPA. 1974-1978)

Verificou-se que, imediatamente após uma queimada para limpeza do terreno, se encon. travam ainda alguns ácaros e colêmbolas-vivas a $5 \mathrm{~cm}$ de profundidade, mostrando que. nestes pontos, a temperatura não ultrapassou limites biológicos (INPA, 1974-1978).

Descobriu-se que insetos tisanópteros (Liothrips adisi e Liothrips diabolica) são capazes de veicular um Hyphomycete e plantas de guaraná, provocando a murcha das folhas jovens e entumescimento e perda dos botões florais. Os trips têm como inimigo natural formiga do gênero Camponotus, que vieram a controlar efetivamente estes vetores de fungos. Uma poda das plantas doentes determinou o desa. parecimento dos fungos, o que mostra as pos. sibilidades de controle desta doença sem 0 uso de biocidas (INPA, 1974-1978)

No exercício de 1979-1980, na administração do Dr. Eneas Salati, o Departamento de Ecologia teve como responsável o Pesquisador Dr. Herbert Otto Roger Schubart funcionando com quatro divisões de pesquisas: Ciências do Ambiente, voltada para o estudo do ambien. te físico e químico dos organismos; enfatizando os grandes ciclos da água, do carbono, dos nutrientes minerais, bem como o balanço de energia, nos grandes ecossistemas da Amazônia; Bioecologia, voltada para o estudo da ecologia de populações e comunidades biológicas incluindo também o Homem; Limnologia, dedicando-se ao estudo dos processos ecológicos nos rios e lagos da Amazônia e Entomologia. voltada para o estudo da sistemática e ecologia dos insetos. O Departamento conta com a colaboração de 31 pesquisadores sendo 14 Ph.D (3 visitantes); 9 M.Sc (1 visitante) e 8 graduados.

Como não poderia deixar de ser, muitas das atividades do Departamento estão sendo concentrados em torno de alguns problemas que exigem abordagem multidisciplinar. E o que está acontecendo com o projeto da divisão de Limnologia, ainda de implantação recen. te. É o que vem acontecendo, há mais tempo no estudo integrado da ecologia da floresta de terra firme, utilizando uma bacia hidrográfica como unidade de estudo. Este programa fundamental para o manejo sustentável das florestas, vem obtendo apoio financeiro da OEA, da SUFRAMA, do Programa das Nações Unldas para o Desenvolvimento, isto através de convênio com a SUDAM, e, mais ainda recen temente este programa foi incluído no projeto de manejo ecológico da floresta tropical financiado pelo BID/FINEP (Fig. 3). Nele participam todas as Divisões, à exceção da Divisão de Limnologia. Para este programa, estão sendo canalizados também os convênios de coo. peração internacional, como já é o caso do convênio entre CNPq/INPA e os CNRS da França. 


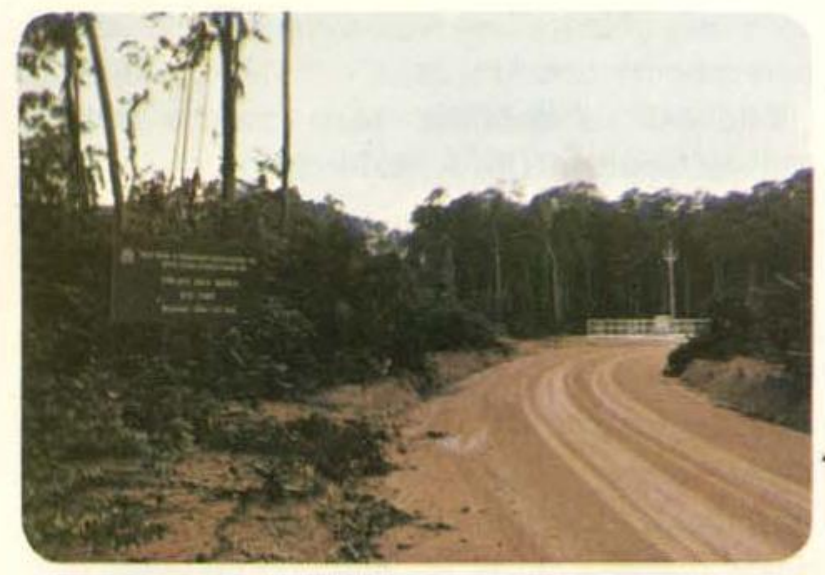

Fig. 3-Area do Projeto "Bacia Modelo", localizada na ZF-02 Rodovia Manaus-Caracaraí.

Outro projeto multidisciplinar é o Tamanho Mínimo Crítico de Ecossistemas, realizado em convênio entre o INPA/CNPq e NSF, que tem como objetivo estudar processos de extınção de populações, recolonização, e manutenção da diversidade biológica em florestas de terra firme, tendo portanto relevância para o manejo e conservação dos recursos biológicos da Amazônia.

A Divisão de Ciências do Ambiente, tendo como responsável a Pesquisadora Dra. Maria de Nazaré Góes Ribeiro, vem desenvolvendo pesquisas referentes ao meso e microclima em bacias representativas do ecossistema florestal na Amazônia Central.

Em virtude das constantes indagações com respeito às possiveis modificações ecológicas que poderiam ocorrer na Região Amazônica, com a substituição das florestas por outros ti. pos de cobertura vegetal, desenvolvem-se atividades de pesquisas em bacias hidrográficas com características semelhantes e represen. tativas da Bacia Amazônica. Em uma das bacias hidrográficas localizadas em áreas do Instituto Nacional de Pesquisas da Amazônia (INPA), procedem-se a estudos referentes às relações existentes entre os diferentes componentes do ciclo hidrológico, cuja vegetação se encontra no seu estado natural, não tendo sido submetida à exploração modificadora ou, melhor dizendo, não perturbada. Recentemente, esse trabalho foi dinamizado com a colabo. ração do Projeto BRA/72/010 das Nações Uni- das. Na outra bacia hidrográfica, está sendo iniciado um trabalho de pesquisas semelhantes e deverão ser feitas culturas de plantas frutíferas, lactíferas, oleíferas, odoríferas e manejo florestal.

Deste modo, na Bacia Hidrográfica Modelo, não perturbada, foi instalada uma torre metálica com 42 metros de altura, dentro da flo. resta, a fim de serem estudados os gradientes de temperatura, umidade, $\mathrm{CO}_{2}$ e energia, determinados o balanço hídrico, balanço de ra. diação e de nutrientes (Fig 4).

\section{PRINCIPAIS RESULTADOS CIENTÍFICOS :}

Medidas de radiação solar global ao nivel do solo $(\mathrm{Qg})$ com pireliômetro de precisão Eppley foram realizadas em Manaus no período 1977-1979. Os maiores valores médios men. sais observaram-se nos meses de setembro

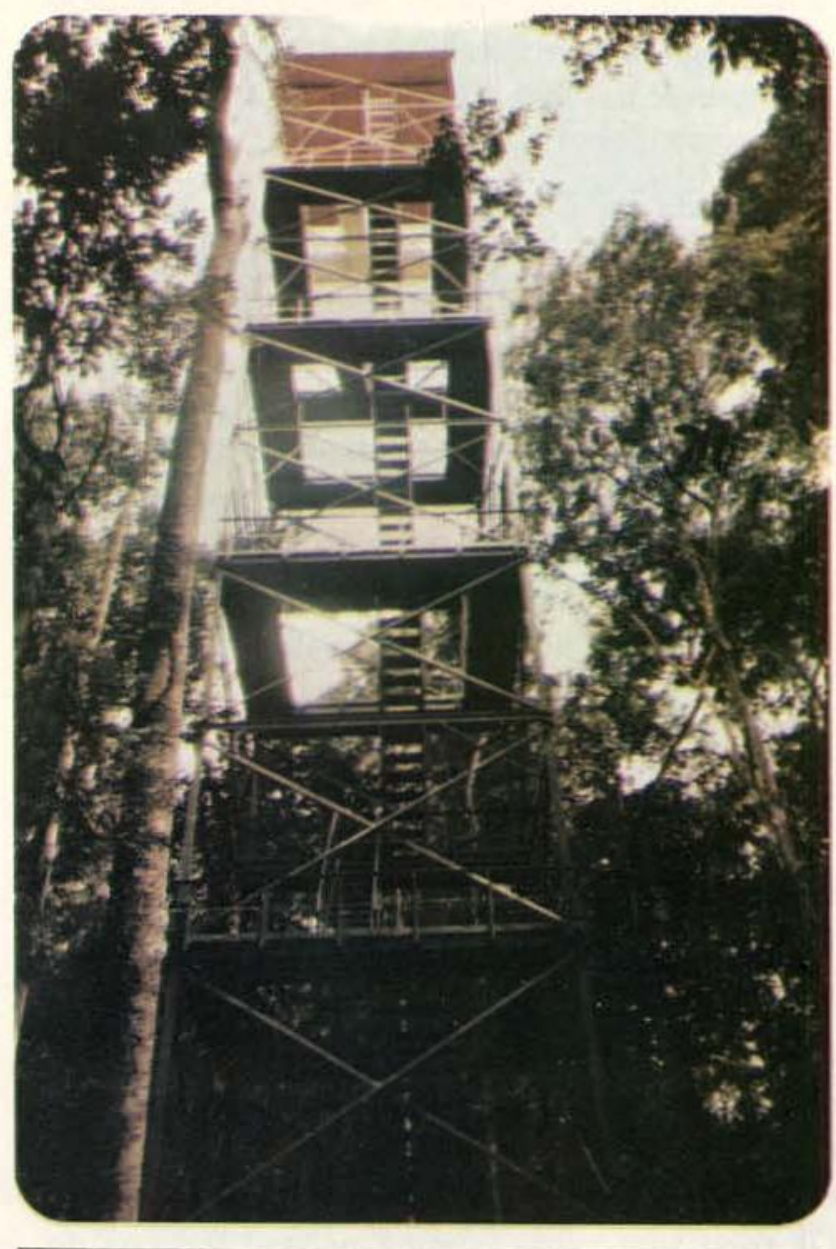

Fig. 4 - Torre metálica instalada na Bacia Hidrográfica Modelo. 
outubro/78 e os menores em Janeiro-fevereiro/78, estando esta distribuiçăo regulada pelo sistema de nuvens convectivas locais. Espera. se que, ao longo da Bacia Amazônica em re. glões de distribuição de nuvens e precipitação semelhante, a distribuição seja idêntica (Ribeiro et al., 1980).

Com medidas de radiação solar global efe tuadas no perodo 1969-1979, na Reserva Ducke do INPA, utilizando radiômetro Bellani, fol determinado um balanço de radiação de onda curta a partir dos valores médios mensais dos fluxos de radiação solar ( $\mathrm{K}$ ). O estudo oferece subsídios a todos os interessados nos problemas das fontes alternativas de energia, na atualidade (Ribeiro et al., 1980).

$\mathrm{O}$ balanço de radiação solar de ondas curtas foi medido em floresta tropical úmida, em local típico das "matas de baixio", no igarapé do Barro Branco, Reserva Ducke, Manaus. Os valores do fluxo $\mathrm{K}$ foram : 419 chegando em cima do dossel; 239 retidos na floresta; 107 atingiu o solo, e o albedo foi de $17,5 \%$.

Os valores do fluxo de PI, foram : $188 \mathrm{em}$ cima do dossel; 123 retido na floresta; 52 atingiu o solo e o albedo foi de $7 \%$.

Floristicamente, esse tipo de "mata de baixio" é muito heterogênea (Santos et al., 1980).

Estudando o clima de Manaus-AM, com dados climatológicos referentes ao período 19651973, concluiu-se que a evapotranspiração po. tencial deve ser aproximadamente igual a eva. potranspiração real durante quase todo o ano, à exceção dos meses de déficit de água no solo (agosto, setembro, outubro) (Ribeiro, 1979).

Medidas tensiométricas sugerem a exis. tência de correlação entre umidade do solo e transpiração das árvores. A transpiração influencia em grande parte a secagem do solo até uma profundidade de $1,0 \mathrm{~m}$ (Fig. 5).

No período de seca, os valores ultrapassam a -850 milibar, valor típico das áreas semi-áridas (INPA, 1979)

De um modo genérico, a maior concentração de vapor d'água atmosférico ocorre entre Manaus e Iquitos. Estimou-se em $35 \mathrm{~mm}$ 。 valor médio da água precipitável sobre a bacia Amazônica, bem como, em $18,2 \%$ o valor da

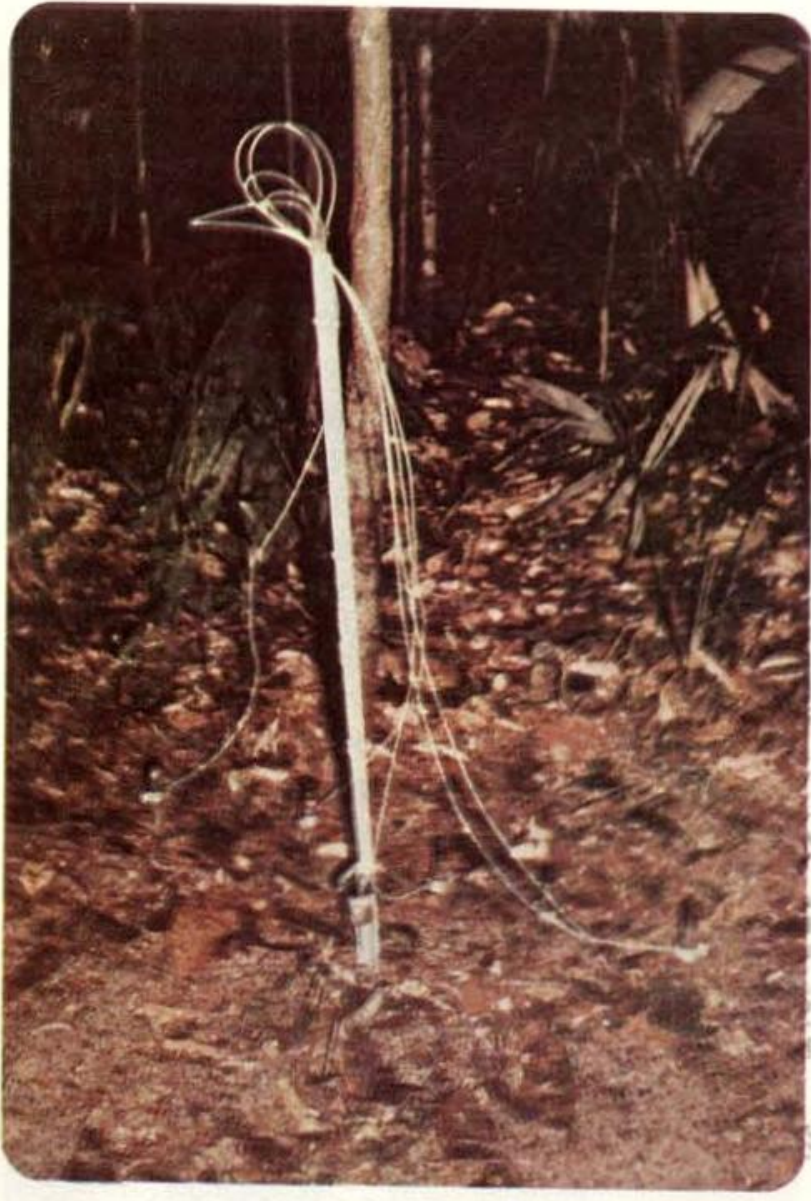

Fig. 5 - Tensiômetro, aparelho para medir a saturação água no solo.

eficiência da precipitação para a Região, e um tempo de reciclagem do vapor d'água de apro. ximadamente 5,5 dias (Marques et al., 1979) .

Trabalhos preliminares demonstram haver uma variação nas concentrações de ${ }^{18} \mathrm{O}$ e $\mathrm{D}$ águas dos rios da bacia Amazônica. As diferentes concentrações de ${ }^{18} \mathrm{O}$ e $\mathrm{D}$ nas águas dos afluentes do Amazonas, demonstram ainda, a variabilidade desses isótopos nas chuvas de diversas sub-regiões (Dall'Olio et al., 1979).

A composição química das águas da ba cia do rio Parauari-Maués-Açu, é nitidamente influenciada pelas estações do ano, com variações sazonais, de acordo com as altera ções do nível das águas e ocorrências climáticas (Bringel, 1980).

A região do Janauacá é dependente do rio Solimões sofrendo variações sazonais de acordo com as alterações do nível das águas e ocorrências climáticas. 
As migrações de peixes estão condicionadas pelos seguintes fatores ecológicos: temperatura, concentração de oxigênio, concentração de sais, concentração de $\mathrm{H}_{2} \mathrm{~S}$, precipitação pluviométrica, decréscimo de espaço e alimentos (Santos, 1979).

Durante o processo fotossintético, ocorre um fracionamento isotópico considerável de carbono, ficando o carbono absorvido pelas plantas com concentração menor ${ }^{13} \mathrm{C}$ do que o $\mathrm{CO}_{2}$ do ar atmosférico. As plantas de ciclo C-3 e C-4 têm valores de ${ }^{13} \mathrm{C}$ cerca de $20 \%$ menores do que $0 \mathrm{CO}_{2}$ do ar (Matsui et al., 1979).

A Divisão de Bioecologia tendo como responsável o pesquisador Herbert Otto Rober Schubart, vem desenvolvendo pesquisas relacionadas com o estudo da ecologia de populações e comunidades biológicas, obtendo os seguintes resultados científicos:

A população de árvores da família Lecythidaceae existentes em 5,2 ha de floresta de ter ra firme apresenta uma densidade de 7,3 árvores por hectare $(12,5 \%$ do total de árvores) repartidas em cerca de 16 espécies, a maioria de gênero Eschweilera. A distribuição populacional da família é típica de plantas tolerantes à sombra (tipo $\mathrm{J}$ reverso) e com indicações de um elevado potencial para regeneração natural (Rankin, 1980).

A densidade de plântulas de 7 espécies de árvores variou de 36 a $642 \mathrm{em}$ blocos de $1 \mathrm{~m} \mathrm{x}$ $5 \mathrm{~m}$. Num caso, a produção inteira de uma árvore de Seleronema micranthum foi etiquetada no campo, resultando 295 plântulas em $15 \mathrm{~m}^{2}$. A germinação de sementes possibilitou a correlação de plântulas com as matrizes de 20 espécies diferentes de árvores; uma coleção de sements, frutos e plântulas está sendo feita como apoio a esta pesquisa sobre paarões de mortalidade de plântulas sob condições naturais na floresta (INPA, 1980).

Em 6 igarapés florestais na região de Manaus, foram discriminadas até agora 130 morfoespécies de tecamebas. A distribuição quantitativa e qualitativa das morfoespécies e características para os igarapés e há diferenças na composição de espécies entre igara. Fés de água preta e água cristalina. A alta diversidade e densidade das tecamebas no sis- tema fluvial da América Central e o padrão de distribuição sugerem estes organismos bons indicadores biológicos da qualidade física e química das águas (INPA, 1980).

A taxa de decomposição da serapilheira na floresta de terra firme sobre latossolo amarelo pesado é cerca de 2 vezes maior do que na floresta primária de baixio, sobre solo are. rioso hidromórfico, mesmo durante os meses chuvosos, quando o processo de decomposi ção é mais rápido (INPA, 1980).

A diversidade de espécies epigeicas de insetos da ordem Collembola foi menor (14 espécies) numa capoeira de 4 anos do que na mata primária (2 espécies) sobre o mesmo tipo de solo. (INPA, 1980).

Nas áreas de colonização da Transamazônica e de Rondônia, constata-se que : (a) a substituição rápida dos colonos na Transamazônica por recém-chegados está expandindo a área de pastagem em relação às culturas anuais; (b) a pastagem tem poucas possibilidades de tornar-se uma forma sustentável de uso da terra; (c) as culturas perenes também estão aumentando, embora a área total ainda seja muito pequena em relação às áreas de pastagens; (d) na Transamazônia, a cultura da pimenta-do-reino vem sendo atacada pelo fungo Fusarium solari f. piperi; comprometendo seriamente a sustentabilidade desta cultura, a longo prazo (INPA, 1980).

Os índios Tukano, agricultores-pescadores da região do alto rio Negro, proíbem a derrubada da mata às margens dos rios, ligada à floresta por corredores que permitem a passagem de polinizadores não voadores. As consequëências dessa prática sobre o potencial agrícola e o rendimento da pesca estão sendo avaliadas.

Durante um estudo ecológico dos morcegos, na região de Manaus, foram analisados, posteriormente soltos, 1300 exemplares, resultando a ocorrência de 55 espécies diferentes; 53 espécies de plantas tiveram seus produtos utilizados por morcegos, demonstrando que estes mamíferos são muito importante na distribuição e polinização dos vegetais na região tropical. 
O jacaré-açu (Melanosuchus niger) reage mal à caça e atingiu o ponto de extinção comercial; ao contrário o jacaré-tinga (Caimancrocodilus) que pode, comparativamente, suportar um alto nível de caça.

Estudo sobre o comportamento social e a ecologia do Sagüi de Manaus (Saguinus bicolor) estão sendo realizadas nas matas próximas do igarapé Tarumã-Açu, nas margens do rio Negro, para obtenção de dados relativos ao comportamento alimentar, ciclos diários de atividades, comportamento reprodutivo, interação intra e interespecificas e o uso do espaço por um grupo desta espécie (INPA, 1980).

A Divisão de Limnologia, tendo como responsável o Pesquisadur Assistente Antonio dos Santos, continua suas pesquisas limnológicas nos rios e lagos da Amazônia Central.

No reservatório de UHE Curuá-Una, foi observado que o abaixamento do nível da água é uma das estratégias para melhorar a qualidade da água com relação à anoxia e produção de $\mathrm{H}_{2} \mathrm{~S}$, pois, uma corrente de fundo com bastante oxigênio promove uma rápida oxidação dos sulfetos e sulfatos modificando assim as condições redutoras de hipolimínio. Esta estratégia deverá ser a solução para minimizar os problemas de formação de gases tóxicos nos pequenos reservatórios (menor ou igual a $100 \mathrm{~km}^{2}$ de área alagada) e sistemas de baixa queda (INPA, 1980).

No lago Jacaretinga - Careiro-AM (pouco profundo) foi detectada pela primeira vez a presença de um termoclima.

A Divisão de Entomologia, tendo como res. ponsável o Pesquisador Norman Penny, vem dando continuidade às pesquisas entomológi. cas de campo e laboratório, com manutenção da coleção de insetos do INPA e desenvolvimento das atividades:

Observações ecológicas e contribuição da Sistemática no conhecimento das espécies (Micropezidae-Diptera) da Amazônia Central (Albuquerque, 1980).

Estudos taxonômicos de neuropteros e mecópteros da Amazônia. Em homópteros aleirodídeos foram descritas 3 novas espécies (Penny \& Arias, 1981a, b).
Aspectos da associação entre fórmigas do gênero Azteca e plantas do gênero Cecropia, do que foi observada uma relação mutualística entre estes gêneros, inibindo certos herbívo. ros que atacam a Cecropia, enquanto a formiga utiliza a árvore como abrigo.

Levantamento dos ectoparasitas de mamiferos e aves de interesse veterinário e médico contido nas Siphonaptera, Mallophaga, Ano. plura, Pupipara e Acarina.

Apreciação do desenvolvimento de ovários anômalos em Passalus convexus Dalman, 1817 e estudos de exemplares de 13 espécies dos gêneros Verres, Venturius e Passalus (INPA, 1980).

Em abril de 1980, foi inaugurado o Labora. tório de Radioisótopos do Departamento de Ecologia (Fig. 6).

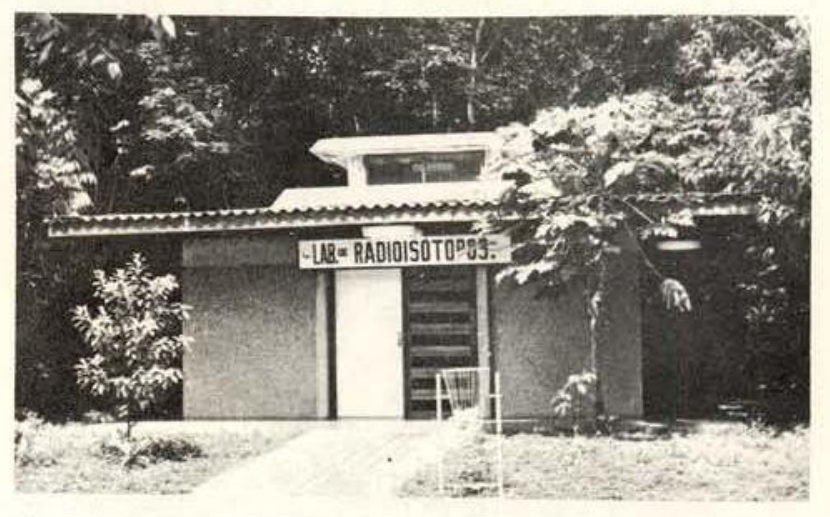

Fig. 6 - Laboratório de Radioisótopos - sede do INPA.

\section{SUMMARY}

The Department of Ecology of the National Research institute of the Amazon (INPA) was founded in 1970 under the name "Sector of Environmental Factors", made up of the Laboratories of Climatology, Hydrology, Limnology and Soil Biology.

In 1971 institutional reorganization by the then $\mathrm{Di}$ rector of INPA, Dr. Paulo de Almeida Machado, resulted in the transformation of the Sector of Environmental Factors to the Division of Environmental Science

Em 1975 further restruturing ereated the Department of Ecology and Soil Biology.

Since 1979 the Department of Ecology has been composed of 4 Research Divisions: Environmental Sciences, Bio-Ecology, Limnology and Entomology. It's research activities are centered on studies of the phy- 
sical and chemical environmental of organisms, with emphasis on the local regional cycles of water, carbon and mineral nutrients, as well as energy budgets in the major ecosystems of the Amazon Basin; on the study of the ecology of populations and biological communities, including those of Humankind; on the study of ecological processes of the systematics and ecology of insects.

The Department has a staff of 31 researchers, including $14 \mathrm{Ph} . \mathrm{D}$ (3 visitor), 9 M.S. (1 visitor) and 9 B.S. scientists.

\section{REFERENNCIAS BIBLIOGRAFICAS}

ALBUQUERQUE, L.P. de

1980 - Estudo dos micropezídeos da Bacia Amazônica. I. Acta Amazonica, 9 (3): 659-670

BRINGEL, S.R.B.

1980 - Hidroquímica da Bacia do rio ParauariMaués Açu. Tese de Mestrado. ESALQUSP. Piracicaba-SP.

BRINKMANN, W.L.F.

1971 - Light Environment in Tropical Rain Forest of Central Amazonia. Acta Amazonica, 1 (2): $37-49$.

1972 - Scattered Light in a Flood-plain Lake of Central Amazonia. Acta Amazonica, 2 (2): 87-90.

P.RINKMANN, W.L.F. \& NASCIMENTO, J.C. do

1973 - The effect of slash and burn agriculture on plant nutrients in the Tertiary Region of Central Amazonia. Acta Amazonica, 3 (1). 55-61.

BRINKMANN, W.L.G. \& RIBEIRO, M.N.G.

1972 - Air temperatures in Central Amazonia. III. Vertical Temperature Distribuition on as clearcut Area and in a Secondary Forest near Manaus (Cold Front Condition July 10 th 1969). Acta Amazonica, 2 (3): 25-29.

BRINKMANN, W.L.F.; RIBEIRO, M.N.G. \& PATE, J.B. 1971a - Soil Temperatures in Terciary Region of Central Amazonia. I. Latosol under tropical rain forest. Suplemento Acta Amazonica. Vol. 1. n. 1.

$1971 b$ - Soil Temperatures in ter Terciary Region of Central Amazonia. II. Cleared white sand areas. Suplemento Acta Amazonica. Vol. 1. $\mathrm{n} .^{\circ} 2$.

BRINKMANN, W.L.F. \& SANTOS, A. dos

1971 - Natural waters in Amazonia. V. Soluble magnesium properties, In Turrialba, 21, 4: 459-465.

1973 - Natural waters in Amazonia. VI. Soluble alcium Properties. Acta Amazonica, 3 (2): 33-40.

DALL'OLIO, A; SALATI, E.; AZEVEDO, C.T.; MATSUI, E.

1979 - Modelo de fracionamento isotópico da água na bacia Amazônica. Acta Amazonica, 9 (4): 675-687.
DECICO, A.; SANTOS, U.M.; RIBEIRO, M.N.G.;

SALATI, E.

1977 - Estudos climatológicos da Reserva Florestal Ducke, Manaus-AM. I. Geotemperaturas Acta Amazonica, 7 (4): 485-494.

GUARIM, V.L.S. dos

1979 - Ocorrência e distribuição de Chromobacterium violaceum (Schrocter) Bergozini 1881, na Amazônia Central. Acta Amazonica, 3 (3): 501-506.

MARQUES, J.; SANTOS, J.M. dos; SALATI, E.

1978 - Considerações sobre os ventos na Regiāo Amazônica. Acta Amazonica, 8 (1): 110-113.

1979 - O armazenamento atmosférico do vapor sobre a região Amazônica. Acta Amazonica, 9 (4): 715-721.

MARQUES, J.; SANTOS, J.M. dos; VILLA NOVA, N.N.; SALATI, E.

1977 - Precipitable water and water vapor between Belém and Manaus. Acta Amazonica, 7 (3): 355-362.

MATSUI, E.; SALATI, E.; BRINKMANN, W.L.F.;

FRIEDMANN, I.

1972 - Vazões relativas dos rios Negro e Solimões através das concentrações de $18_{0}$. Acta Amazonica, 2 (3): 31-46.

MATSUI, E.; SALATI, E.; RIBEIRO, M.N.G.

1979 - Ciclo de $\mathrm{CO}_{2}$ : Os valores de $\mathrm{S}{ }^{12} \mathrm{C}$ do $\mathrm{CO}_{2}$ do ar e do carbono das plantas. Boletim do CENA.

FENNY, N.D. \& ARIAS, J.R.

1981a- A new species of Ceraleurodius from Amazon Basin (Momoptera: Aleyrodidae3. Acta Amazonica, 10 (4): 903-905.

1981b- Two new species of Bakerius from the Amazon Basin (Homoptera: Aleyrodidae). Acta Amazonica, 10 (3): 691-695.

FiANKIN, J

1980 - Diversidade e Dispersão de Lecythidaceae na floresta de terra firme na Amazônia Central. Ciência e Cultura. Supl. 32 (7).

INPA - Instituto Nacional de Pesquisas da Amazônia 1970 - RELATÓRIO ANUAL, Manaus-AM.

1971 - RELATÓRIO ANUAL, Manaus-AM.

1972 - RELATÓRIO ANUAL, Manaus-AM.

1973 - RELATÓRIO ANUAL, Manaus-AM

1974 - 1978 - RELATÓRIO QUADRANGULAR, Manaus-AM

1979 - RELATÓRIO ANUAL, Manaus-AM

1980 - RELATÓRIO ANUAL DO DEPARTAMENTO DE ECOLOGIA do INPA, Manaus-AM.

RIBEIRO, M.N.G.

1976 - Aspectos climatológicos de Manaus. Acta Amazonica, 6 (2): 229-233.

1977 - Anuário Meteorológico do INPA: edições 1965-66-67-68-69-70-71-72-73-74-75-76. In3tituto Nacional de Pesquisas da Amazônia. Manaus. 
RIBEIRO, M.N.G. \& SANTOS, A. dos

1975 - Observações microclimáticas no Ecossistema "Campina Amazônica", 5 (2): 183-189.

RIBEIRO, M.N.G.; SALATI, E.; SANTOS J.M. dos

1980 - Análises das medidas de radiação solar global da Reserva Ducke-Manaus, no período 1970-1979. Trabalho apresentado no I Congresso Brasileiro de Meteorologia. Campina Grande-PB.

FIBEIRO, M.N.G.; SALATI, E.; VILLA NOVA, N.A.; DEMÉTRIO, C.G.

1980 - Radiação solar disponível em Manaus (AM) e suas relações com duração do brilho solar. Trabalho apresentado no I Congresso Brasileiro de Meteorologia. Campina Grande-PB.

RIBEIRO, M.N.G. \& VILLA NOVA, N.A.

1979 - Estudos climatológicos da Reserva Florestal Ducke, Manaus-AM. III. Evapotranspiração. Acta Amazonica, 9 (2): 305-309.

RUFINO, E.O. \& SCHUBART, H.O.R.

1974 - Uma experiência sobre a nutrição de Onchiurus cunhai Arlé, 1970 (Insecta, Collembola), com notas sobre a sua ecologia Acta Amazonica, 4 (3): 53-55.

SANTOS, A. dos \& RIBEIRO, M.N.G.

1975 - Nitrogênio na água do solo do Ecossistema "Campina Amazônica". Acta Amazonica, 5 (2): 173-182.

SANTOS, J.M. dos; SALATI, E.; ARAUJO, V.C. ; ALVES, L.F.; BUENO, C.R.; CARDENAS, J.D.R. \& MASCARENHAS, B.M.

1980 - Balanço de Radiação Solar de ondas curtas em floresta tropical (Reserva Ducke-Ma- naus). Trabalho apresentado no I Congresso Brasileiro de Meteorologia. Campina Grande-PB.

SANTOS, U.M.

1980 - Aspectos limnológicos do lago grande de Jutaí (Amazônia Central) face as alteraçōes químicas do meio hídrico da região. Acta Amazonica, 10 (4): 797-822.

1979 - Observaçōes Limnológicas sobre as asfixia e migração de peixes na Amazônia Central. Ciência e Cultura. Vol. 31 (9): 1033-1040.

VILLA NOVA, N.A.; RIBEIRO, M.N.G.; NOBRE, C.A.; SALATI, E.

1978 - Radiação Solar em Manaus. Acta Amazônica, 8 (3): 417-421.

VILLA NOVA, N.A.; SALATI, E.; MATSUI, E.

1976 - Estimativa de evapotranspiração na Bacia Amazônica. Acta Amazonica, 6 (2): 215-228.

VILLA. NOVA, N.A.; SALATI, E.; SANTOS, J.M. dos; RIBEIRO, M.N.G.

1976 - Coeficiente de transmissão de radiação solar em Manaus em junho. Acta Amazonica, 6 (3): 319-322.

WALKER, I.

1978 - Rede de alimentação de invertebrados das águas pretas do sistema rio Negro. 1. Observação sobre a predação de uma Ameba do tipo Ameba discoides. Acta Amazonica, 8 (3): 423-438.

WALKER, I. \& LAGES, M.T.

1980 - Adaptation of constant effect sampling and of removal trapping for the estimation of population of microscopia organism in dense substrates. Acta Amazonica, 10 (3): 535544 . 